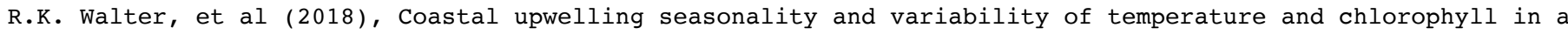
small coastal embayment, Continental Shelf Research, 154, 9-18.

\title{
Coastal upwelling seasonality and variability of temperature and chlorophyll in a small coastal embayment
}

\author{
Ryan K. Walter ${ }^{\mathrm{a}, *}$, Kevin J. Armenta ${ }^{\mathrm{a}}$, Brandon Shearer ${ }^{\mathrm{b}}$, Ian Robbins ${ }^{\mathrm{a}}$, John Steinbeck ${ }^{\mathrm{c}}$ \\ a Physics Department, California Polytechnic State University, San Luis Obispo, CA, USA \\ ${ }^{\mathrm{b}}$ Mathematics Department, California Polytechnic State University, San Luis Obispo, CA, USA \\ ${ }^{\mathrm{c}}$ Tenera Environmental Inc., San Luis Obispo, CA, USA
}

\section{A R T I C L E I N F O}

\section{Keywords:}

Coastal upwelling

Upwelling seasonality

Coastal embayment

Seasonal variability

Upwelling shadow

Temperature and chlorophyll variability

\begin{abstract}
A B S T R A C T
While the seasonality of wind-driven coastal upwelling in eastern boundary upwelling systems has long been established, many studies describe two distinct seasons (upwelling and non-upwelling), a generalized framework that does not capture details relevant to marine ecosystems. In this contribution, we present a more detailed description of the annual cycle and upwelling seasonality for an understudied location along the central California coast. Using both the mean monthly upwelling favorable wind stress and the monthly standard deviation, we define the following seasons (contiguous months) and a transitional period (non-contiguous months): "Winter Storms" season (Dec-Jan-Feb), "Upwelling Transition" period (Mar and Jun), "Peak Upwelling" season (Apr-May), "Upwelling Relaxation" season (Jul-Aug-Sep), and "Winter Transition" season (Oct-Nov). In order to describe the oceanic response to this upwelling wind seasonality, we take advantage of nearly a decade of full water-column measurements of temperature and chlorophyll made using an automated profiling system at the end of the California Polytechnic State University Pier in San Luis Obispo Bay, a small ( $\sim 2 \mathrm{~km}$ wide near study site) and shallow ( $10 \mathrm{~m}$ average bay depth) coastal embayment. Variability and average-year patterns are described inside the bay during the various upwelling seasons. Moreover, the role of the local coastline orientation and topography on bay dynamics is also assessed using long-term measurements collected outside of the bay. The formation of a seasonally variable upwelling shadow system and potential nearshore retention zone is discussed. The observations presented provide a framework on which to study interannual changes to the average-year seasonal cycle, assess the contribution of higher-frequency features to nearshore variability, and better predict dynamically and ecologically important events.
\end{abstract}

\section{Introduction}

Equatorward winds drive coastal upwelling in eastern boundary current upwelling systems around the world (cf. Chavez and Messié, 2009). In the California Current System (CCS), the wind-driven upwelling is forced by the atmospheric circulation and geostrophic winds around the North Pacific High (NPH), a feature that fluctuates seasonally (Huyer, 1983). Along the coastline, the presence of a coastal boundary and highly polarized alongshore winds (see Fewings et al., 2016 and the references therein) results in a shallow offshore (Ekman) transport of surface waters. This process is driven by the earth's rotation (Coriolis) and causes upwelling of cool, nutrient-rich waters from below the surface Ekman layer to the coastal environment. The upwelled waters occur along a narrow $5-30 \mathrm{~km}$ band adjacent to the coastline, a cross-shelf distance that scales latitudinally with the internal Rossby radius of deformation (Checkley and Barth, 2009). These nutrient-rich waters result in elevated levels of primary production and higher trophic level production (Huyer, 1983; Pennington and Chavez, 2000; Chavez and Messié, 2009 and the references therein). Due to the low $\mathrm{pH}$ and dissolved oxygen (DO) content characteristic of subthermocline waters, upwelling can also significantly affect nearshore hypoxia and ocean acidification (OA) (Boehm et al., 2015 and the references therein).

The seasonality of regional upwelling favorable winds in the CCS has long been established, with many studies describing two distinct seasons: the summer upwelling season and the winter non-upwelling season (Huyer, 1983; Dorman and Winant, 1995; Checkley and Barth, 2009 and the references therein; García-Reyes and Largier, 2012 and the references therein; Walter et al., 2014b; Walter and Phelan, 2016). As noted by García-Reyes and Largier (2012), the more widely adopted bimodal (upwelling and non-upwelling) description of upwelling does not encapsulate seasonality features that are important for nearshore

\footnotetext{
* Corresponding author.

E-mail address: rkwalter@calpoly.edu (R.K. Walter).
} 


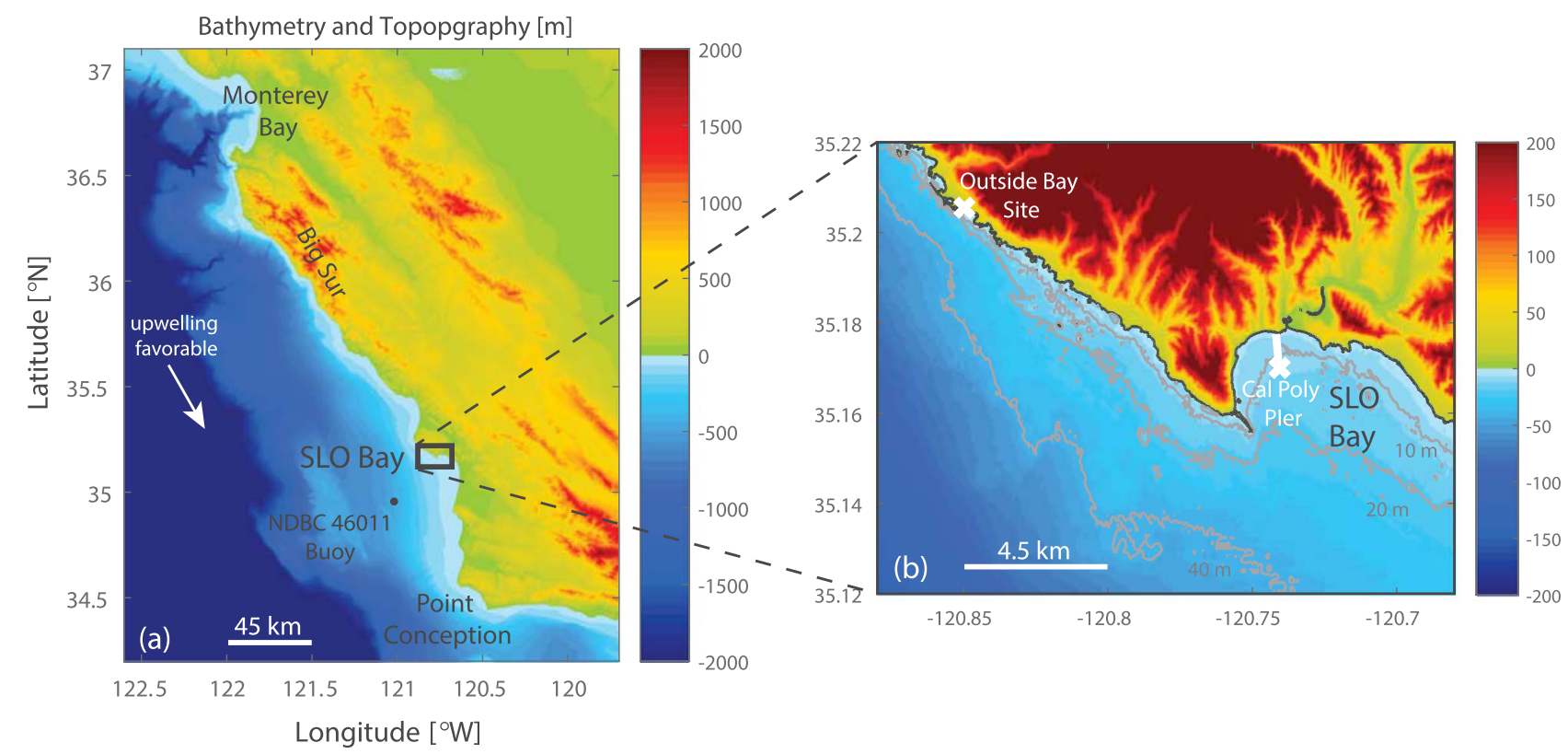

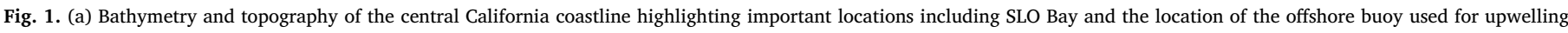

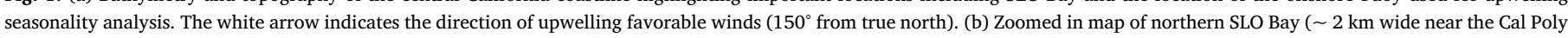

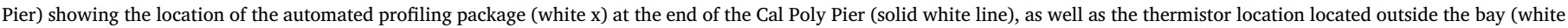
$\mathrm{x})$. The 10,20 , and $40 \mathrm{~m}$ isobaths are shown as gray lines.

ecosystems. This includes the so-called "spring transition" from winter to strong upwelling conditions, an event that has profound consequences for higher-trophic levels (see review by Checkley and Barth, 2009). Additionally, the distribution and abundance of different phytoplankton species, including several species that lead to harmful algal blooms (HABs), fluctuates throughout the year, and particularly within the upwelling season, in response to changing environmental conditions and small-scale physical processes (Gentien et al., 2005; Kudela et al., 2005). A more detailed and temporally-resolved description of upwelling and the oceanic response, beyond the bimodal description, could be useful for the prediction of dynamically and ecologically important events.

Recognizing the importance of upwelling seasonality, García-Reyes and Largier (2012) used long-term wind data measured at offshore buoys along the central and northern California coast $\left(\sim 35-42^{\circ} \mathrm{N}\right)$ to describe the seasonal variability of upwelling favorable winds, as well as the response of the coastal ocean using sea surface temperature (SST) and surface chlorophyll concentrations. Based on the mean and standard deviation of the monthly upwelling-favorable wind stress, they defined three distinct upwelling seasons (with the remaining months categorized as transitional periods): the "Storm Season" (Dec-Jan-Feb) with weak mean and highly variable upwelling winds; the "Upwelling Season" (Apr-May-Jun) with strong mean equatorward winds and large standard deviations due to frequent reversals; and the "Relaxation Season" (Jul-Aug-Sep) with weaker upwelling-favorable winds and low variability (García-Reyes and Largier, 2012). Other studies have also included this third fall relaxation season (also sometimes called the "Oceanic Season"), particularly when describing central California upwelling (Skogsberg, 1936; Largier et al., 1993; Pennington and Chavez, 2000; García-Reyes and Largier, 2012). While the García-Reyes and Largier (2012) study built a strong foundation on which to examine seasonality in central and northern California, there were strong latitudinal differences in the timing, strength, and intensity of the upwelling-favorable winds, as well as the corresponding near-surface oceanic response.

In this contribution, we present a tuning of the annual cycle and upwelling seasons for an understudied location along the central California coast. Likewise, we build on the analysis of García-Reyes and
Largier (2012) by considering the oceanic response throughout the entire water column. A further understanding of the effect of upwelling seasonality on water-column stratification, as well as the vertical distribution of chlorophyll, provides insight into various physical and biological processes such as the vertical mixing and flux of nutrients and other scalars to the surface photic zone, biogeochemical cycling, internal wave and bore dynamics and water column stability, HAB bloom dynamics and patterns of toxicity, and coastal hypoxia/OA (Pennington and Chavez, 2000; Gentien et al., 2005; Kudela et al., 2005; Ryan et al., 2008, 2014; Chavez and Messié, 2009; Checkley and Barth, 2009; Booth et al., 2012; Walter et al., 2012, 2014a, 2014b, 2016; Walter and Phelan, 2016). We take advantage of nearly a decade of full water-column measurements of temperature and chlorophyll made in a small $(\sim 2 \mathrm{~km}$ wide near the study site) and shallow (average bay depth of $\sim 10 \mathrm{~m}$ ) coastal embayment. Despite the ubiquity of small coastal embayments along eastern boundary currents worldwide, there are few long-term time series of full water-column measurements (cf. Pennington and Chavez, 2000). Here, we introduce an automated profiling system at the end of the California Polytechnic State University (Cal Poly) Pier located in San Luis Obispo (SLO) Bay. We describe the seasonal dynamics and average-year patterns of temperature and chlorophyll in relation to the upwelling seasons defined using local offshore wind characteristics. This represents one of the only studies documenting seasonal cycles of nearshore variability throughout the water column from a long-term data set in a poorly sampled region along the California coastline stretching from south of Monterey Bay and the Big Sur Coastline to north of Point Conception, the latter of which is a major marine biogeographic boundary (Blanchette et al., 2007; Checkley and Barth, 2009; Chao et al., 2017). The focus of this paper is the examination of seasonal variability; higher-frequency variability in response to upwelling and relaxation cycles and local diurnal wind forcing will be reported elsewhere (e.g., Walter et al., 2017). Finally, we consider the role that the local coastline orientation and topography have on bay dynamics and document the formation of a seasonally variable upwelling shadow and nearshore retention zone in the bay. 


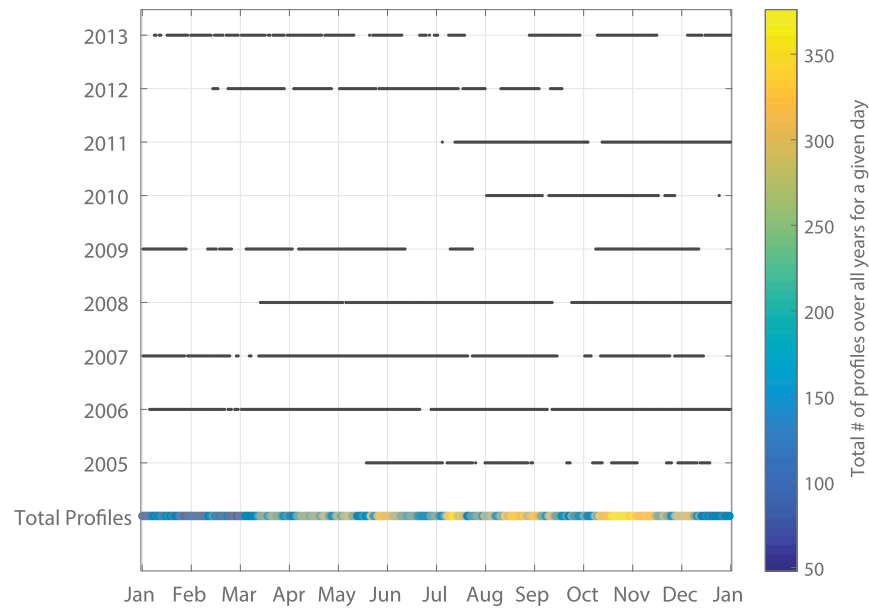

Fig. 2. Daily CTD data availability for all years (black), as well as the total number of profiles over all years (2005-2013) available each day (colorbar). Note that chlorophyll measurements were added in August 2007 and coincide with the available CTD measurements from that point forward.

\section{Experimental setup and methods}

\subsection{Field site and data}

SLO Bay is a small $(\sim 2 \mathrm{~km}$ wide in the northern portions of the bay), shallow (average bay depth of $\sim 10 \mathrm{~m}$ ), and semi-enclosed coastal embayment located along the eastern boundary of the Pacific Ocean (Fig. 1a). The embayment is located along an understudied stretch of the central California coast and contains considerable ecological diversity including giant kelp forests. SLO Bay also features several tourist destinations, a local fishing port, a small breakwater that helps provide protection from large swells from the northwest, and several piers including the Cal Poly Pier. The Cal Poly Pier extends nearly $1 \mathrm{~km}$ out into the center of the northern portion of the bay where local water depths are just over $10 \mathrm{~m}$ (Fig. 1b).

At the end of the Cal Poly Pier is an automated profiling system that has been collecting oceanographic data intermittently for over a decade (2005-present). In this contribution, we focus our analysis on the period from 2005 to 2013 (data availability shown in Fig. 2), as to not bias seasonal descriptions with the anomalously warm conditions measured during the North Pacific marine heatwave from 2014 to 2016 (e.g., "the warm Blob" and to a lesser degree El Niño conditions; Bond et al., 2015; Gentemann et al., 2016). Marine heatwave conditions from the profiler data will be reported in a future contribution (Largier et al., in prep). The profiling system is comprised of an instrument package connected to a winch, which is programmed to take vertical profiles throughout the water column (nominal water depth of $\sim 10 \mathrm{~m}$ ) every $30 \mathrm{~min}$. The instrument package was originally equipped with a Sea-Bird Electronics 37 SIP conductivity-temperature-depth (CTD) sensor. In 2017, this sensor was replaced with a Sea-Bird 19+ profiling CTD, which provides more accurate conductivity (and hence salinity) measurements. Given the inaccuracy in the conductivity measurements prior to 2017 , only the temperature and pressure (depth) measurements will be reported here. In August 2007, a Wet Labs Eco FLNTU measuring both chlorophyll- $a$ (hereafter referred to as chlorophyll) and turbidity was installed. Although not analyzed in this paper, the profiler also has a Wet Labs Bioluminescence Assessment Tool (UBAT) and a Wet Labs C-Star Transmissometer, both of which were installed in August 2007. Here we focus our analysis on vertical profiles of the temperature and chlorophyll data, the latter of which will be used as a proxy for biological productivity.

During each vertical profile, the instrument package is lowered to a depth of $1 \mathrm{~m}$ below the surface where it is allowed to equilibrate for approximately a minute before being lowered to the bottom of the water column (nominal water depth of $\sim 10 \mathrm{~m}$ ) and back up at a rate of approximately $0.04-0.05 \mathrm{~m} / \mathrm{s}$. At the end of each profile (approximately every $30 \mathrm{~min}$ ), the instrument package receives an automatic freshwater rinse. All of the instruments sample at $1 \mathrm{~Hz}$ (except the UBAT, which samples at $60 \mathrm{~Hz}$ ) and data streams are collected at the Cal Poly Pier and transmitted to local servers. Instruments are calibrated annually by their respective manufacturers and the measurements are integrated into local ocean-observing efforts supported by the Central and Northern California Ocean Observing System (CeNCOOS) and the Southern California Coastal Ocean Observing System (SCCOOS). While the data collected are foundational measurements for other processes and studies (Chao et al., 2017; Walter et al., 2017), this contribution represents the first comprehensive analysis of the pier profiler data and is meant to provide a basic description of seasonal cycles.

To assess regional wind-driven upwelling, hourly offshore winds were obtained from the National Data Buoy Center (NDBC) Buoy 46011 (Fig. 1a, $\sim 35 \mathrm{~km}$ offshore of SLO Bay). Equatorward upwelling favorable winds were calculated using the local coastline orientation $\left(150^{\circ}\right.$ from true north; Fig. 1a). In order to assess the effect of the semienclosed embayment on the oceanic response to seasonal upwelling, temperature measurements inside the bay (Cal Poly Pier) are compared to those measured outside of the bay along a straight stretch of coastline (Outside Bay site, Fig. 1b). At the Outside Bay site, Tenera Environmental has been collecting temperature nearly continuously since 1978 as part of an ecosystem monitoring project for the Pacific Gas and Electric Co. Diablo Canyon nuclear power plant. In this study, we utilize measurements spanning the same time period as the Cal Poly Pier profiler (2005-2013) from one of the long-term sampling locations (Station SC 1), which is located approximately $1.4 \mathrm{~km}$ downcoast from where the heated effluent from the power plant is discharged. The data collected from Station SC 1 are outside of the effects of the discharge plume and are used in other monitoring studies as control data for comparison with data from locations in the discharge plume (Steinbeck et al., 2005). At SC 1, temperature measurements were collected at 20 min intervals using a Hugrun Seamon Mini thermistor located at a water depth of $3 \mathrm{~m}$ relative to mean lower low water (MLLW). The temperature measurements from the Outside Bay location (i.e., Station SC 1) were linearly interpolated to have the same time interval as the Cal Poly Pier profiler data. To account for local tidal (sea surface height) variations and to provide bounds on the temperature comparisons between the Cal Poly Pier measurements and the Outside Bay measurements, Pier measurements at depths of both 3 and $5 \mathrm{~m}$ are used in the comparison to Outside Bay measurements.

\subsection{Data processing}

Downcast profiles of temperature and chlorophyll were quality controlled by taking into account sensor range limits and applying a median filter to remove outliers greater than five standard deviations from the median during each downcast. This threshold proved to be robust at removing spikes, while still maintaining thin patches of physically plausible data (e.g., phytoplankton thin layers, Sullivan et al., 2010; Durham and Stocker, 2012). Downcast data were binaveraged into $0.5 \mathrm{~m}$ vertical bins starting at $1 \mathrm{~m}$ below the surface to a depth of $9 \mathrm{~m}$. A maximum depth of $9 \mathrm{~m}$ was chosen to maintain a similar number of data points in each vertical bin based on the changing tidal height. Following Pennington and Chavez (2000), an average-year time series was calculated by averaging each year's bin-averaged data within the same 1-day time window over the entire study period.

Time series of upwelling favorable wind stresses were calculated following Large and Pond (1981) assuming a neutrally stable atmospheric boundary layer,

$\tau=\rho C_{d} u_{10}\left|u_{10}\right|$,

where $\rho$ is the density of air, $C_{d}$ is the drag coefficient, and $u_{10}$ is the 
wind speed at $10 \mathrm{~m}$ above the sea surface calculated using the equatorward upwelling favorable wind measured at the buoy ( $5 \mathrm{~m}$ above the sea surface) and the formulation in Large and Pond (1981). While seasonally-averaged values of upwelling favorable wind stress have long been used to describe wind characteristics, these mean values do not accurately capture higher-frequency variability associated with upwelling-relaxation cycles, reversals (along-shore poleward winds), fronts (storms) in winter months, etc. (Send et al., 1987; Checkley and Barth, 2009; García-Reyes and Largier, 2012; Fewings et al., 2016; Walter and Phelan, 2016; Flynn et al., 2017 and the references therein; Walter et al., 2017). Following García-Reyes and Largier (2012), we used a combination of the wind stress mean and standard deviation of the wind stress to describe the wind characteristics and upwelling seasonality. Using all available data over all years (2005-2013) for a particular month, mean upwelling favorable wind stresses were calculated and compared to the monthly variability (i.e., standard deviation of the wind stress). Average monthly temperature and chlorophyll profiles were calculated in a similar manner (i.e., using all available data over all years).

\section{Results}

\subsection{Upwelling seasonality}

Consideration of both the mean monthly upwelling favorable wind stress and the monthly standard deviation (cf. García-Reyes and Largier, 2012) reveals a distinct clustering of the wind data into various seasons and a transitional period (Fig. 3). We adopt the term season to describe contiguous months that occupy clear regions of the wind stress parameter space, while the term period is defined as non-contiguous months that still occupy a distinct portion of the wind stress parameter space. The annual progression of upwelling winds is defined as follows (Fig. 3). During the "Peak Upwelling" season (Apr-May), upwelling winds are the strongest and most variable. Later in the summer and into the early fall (Jul-Aug-Sep, "Upwelling Relaxation" season), the winds are weaker with lower variability. The transition to the winter months (Oct-Nov, "Winter Transition" season) is characterized by higher variability compared to the "Upwelling Relaxation" season. During the winter months (Dec-Jan-Feb, "Winter Storms" season), there is weak upwelling, but high variability. The transition between the "Winter

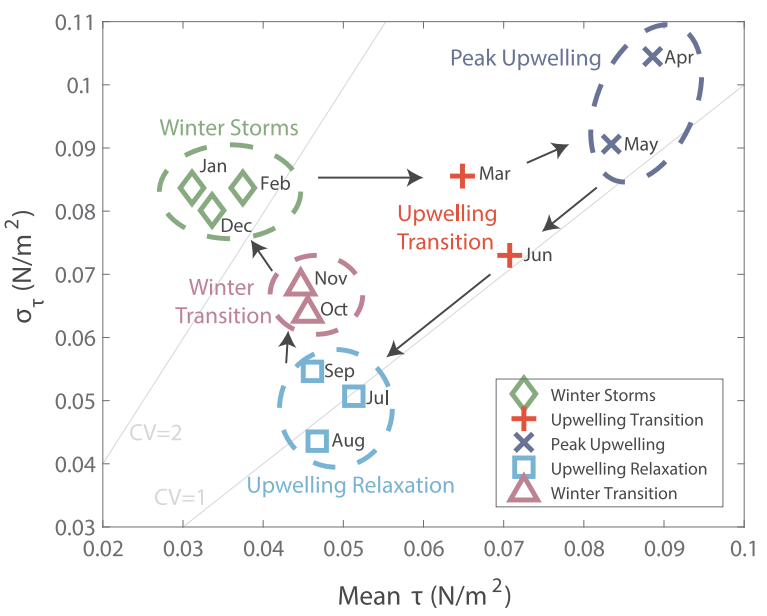

Fig. 3. Monthly variability (standard deviation of the upwelling favorable wind stress) as a function of the monthly mean upwelling favorable wind stress (positive $=$ upwelling favorable, along-shore equatorward) over the entire study period. Colored symbols denote the various upwelling seasons (contiguous months, dotted ellipses around these seasons) and the "Upwelling Transition" period. The black arrows show the temporal progression between seasons and the "Upwelling Transition" period months. The light gray lines denote lines of constant coefficient of variation (CV). Hourly wind data over all years (2005-2013) were used to calculate monthly statistics.

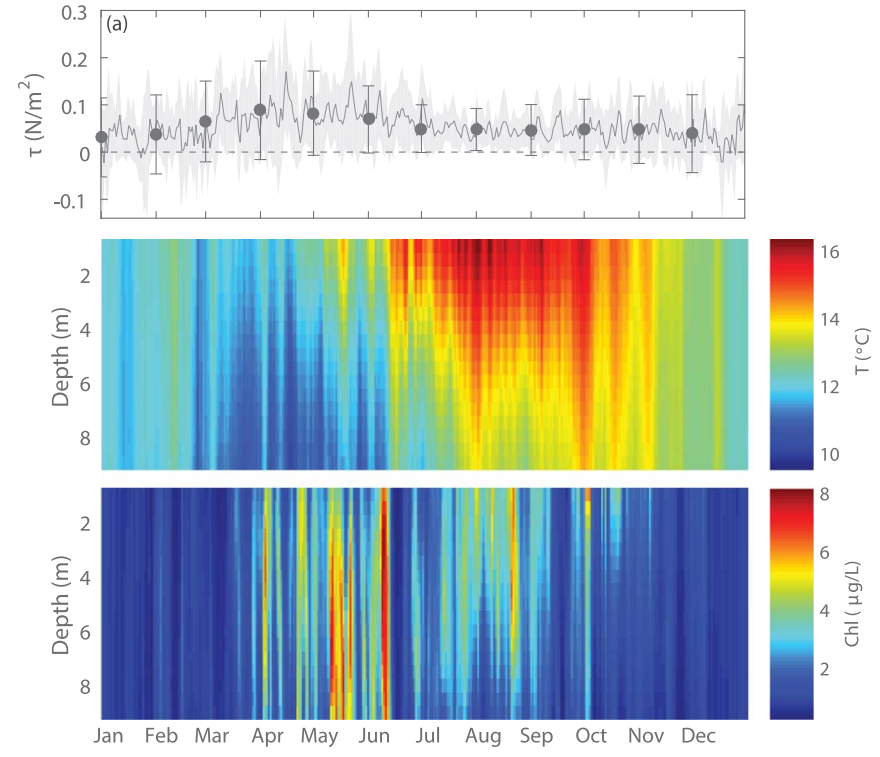

Fig. 4. Average year calculated using data covering the time period from 2005 to 2013 (2007-2013 for chlorophyll). (a) Daily mean (dark gray line) upwelling favorable wind stress (positive $=$ upwelling favorable, along-shore equatorward) and variability (light gray shading represents one standard deviation). Also shown are monthly mean winds (black dots) and variability (black error bars denote one standard deviation). Data are from NDBC buoy 46011 (Fig. 1a). Daily vertical profiles of the mean (b) temperature and (c) chlorophyll concentration from the Cal Poly Pier.

Storms" and "Peak Upwelling" seasons in March, as well as the transition between the "Peak Upwelling" and "Upwelling Relaxation" seasons in June, is termed the "Upwelling Transition" period (i.e., noncontiguous Mar and Jun months, but still distinct in the parameter space). The coefficient of variation (standard deviation divided by the mean) is denoted by gray lines in Fig. 3 and ranges from a minimum value of around 1 during the "Upwelling Relaxation" season to a maximum of about 2 during the "Winter Storms" season.

\subsection{Temperature and chlorophyll}

The average annual cycle of the upwelling favorable wind stress and vertical profiles of both temperature and chlorophyll are depicted in Fig. 4. During the "Peak Upwelling" (Apr-May) season, the strongest upwelling winds coincide with the coldest waters $\left(\sim 10^{\circ} \mathrm{C}\right)$ of the year. These upwelled waters persist for several months along the bottom portion of the water column with minimal vertical stratification. Chlorophyll concentrations, which are more variable in time due to bloom events, also peak during this time of the year. Following a transition into the "Upwelling Relaxation" season (Jul-Aug-Sep), a decrease in upwelling is followed by an increase in near-surface temperatures and the development of a warm layer of water near the surface within SLO Bay. This season is marked by strong vertical temperature stratification that persists until the "Winter Transition" season (Oct-Nov). Enhanced levels of chlorophyll in the near-surface warm layer also persist until October. During the "Winter Storms" season (Dec-Jan-Feb), the water column is well-mixed and chlorophyll concentrations are minimal.

Average monthly profiles of the mean, standard deviation, and vertical gradients of temperature show the evolution of the annual cycle in more detail (Fig. 5). During the "Winter Storms" season (Dec-JanFeb), the mean temperature is uniform throughout the water column, there is minimal temperature variability (as measured by the standard deviation), and the vertical temperature gradient (stratification) is close to zero. After a transition (Mar), the drastic increase in upwelling winds during the "Peak Upwelling" season (Apr-May) is discernible in the mean temperature profiles with a decrease in temperature over the 

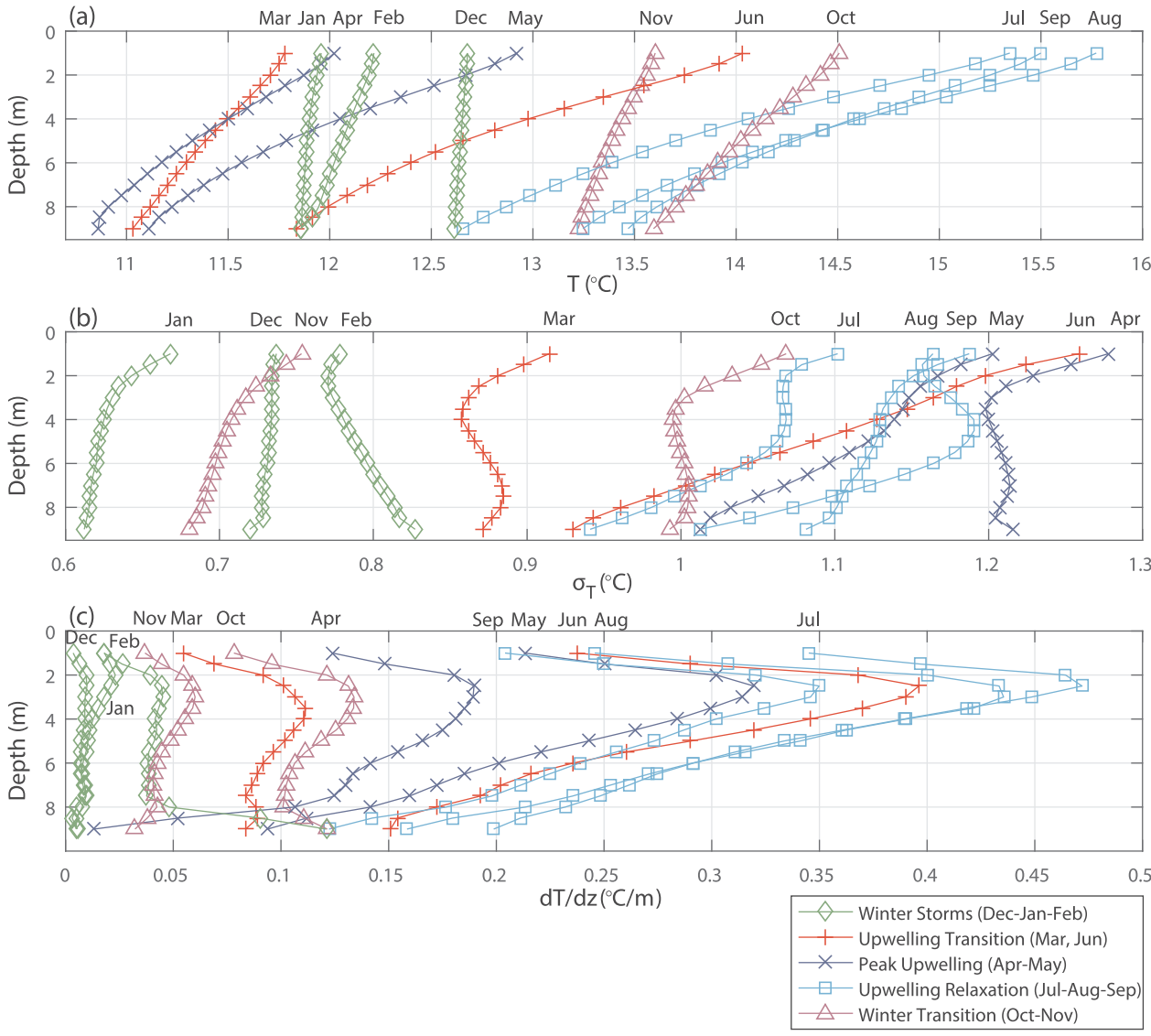

Fig. 5. Monthly vertical profiles calculated over the entire study period (2005-2013) of the (a) mean temperature, (b) temperature variability (monthly standard deviation), and (c) vertical temperature gradients (i.e., stratification). Colored symbols denote the different upwelling seasons (contiguous months) and the "Upwelling Transition" period. bottom portions of the water column. Vertical temperature gradients increase slightly during this time and a near-surface $(\sim 3 \mathrm{~m}$ depth) thermocline begins to develop. The "Peak Upwelling" season also displays the largest standard deviations compared to any other time during the year. Following a transitional month (Jun), the "Upwelling Relaxation" season (Jul-Aug-Sep) is characterized by the warmest surface waters throughout the entire year, enhanced temperature variability, and the strongest vertical stratification observed during the annual cycle with a pronounced thermocline near the surface. During, the "Winter Transition" season (Oct-Nov) the strong vertical stratification begins to erode as the near-surface region cools until returning back to the "Winter Storms" season (Dec-Jan-Feb) profiles.

Similarly, the monthly progression of vertical chlorophyll profiles is highlighted in Fig. 6. During the "Winter Storms" season (Dec-Jan-Feb), mean chlorophyll levels are minimal with almost no vertical gradients and little variability as measured by the monthly standard deviation. As the upwelling winds intensify during the "Peak Upwelling" season (AprMay), average chlorophyll concentrations increase to some of the highest concentrations seen throughout the year and exhibit a local maximum in the middle of the water column (e.g., $\sim 6 \mathrm{~m}$ depth in May). This time of the year also exhibits the largest chlorophyll standard deviation, which is comparable to the mean concentrations and likely driven by bloom events. As the winds subside and the system transitions into the "Upwelling Relaxation" season (Jul-Aug-Sep), chlorophyll concentrations remain high over the upper portions of the water column, but decrease near the bottom, resulting in strong vertical gradients. The near-surface variability in chlorophyll is also pronounced during this season, again comparable to the mean concentrations. The "Winter Transition" season (Oct-Nov) is highlighted by a sharp decline in near-surface chlorophyll (both the mean and standard deviation) and decreasing vertical gradients until returning to the values seen during the "Winter Storms" season (Dec-Jan-Feb).

To investigate the link between biological productivity and upwelling forcing, chlorophyll as a function of upwelling strength is plotted in Fig. 7. The monthly depth-averaged chlorophyll concentration (calculated using the average of all depth-averaged downcast profiles in a particular month for a particular year) as a function of the monthly upwelling favorable wind stress shows considerable year to year variability (Fig. 7a), which is likely due to bloom events (Pennington and Chavez, 2000; Chavez and Messié, 2009; Chavez et al., 2011; García-Reyes and Largier, 2012). The largest average chlorophyll concentrations typically occur during the spring and summer months ("Peak Upwelling" season, "Upwelling Transition" period, and "Upwelling Relaxation" season), while the "Winter Transition" and "Winter Storms" seasons are consistently low-chlorophyll months. Interestingly, the largest chlorophyll concentration months for an individual year are observed for moderate upwelling favorable wind stress (cf. GarcíaReyes and Largier, 2012; García-Reyes et al., 2014). This pattern may be driven by a combination of (1) the mid-range optimum hypotheses presented by Botsford et al. (2006), whereby low winds can lead to nutrient limitations while high winds can lead to advective losses from the shelf [see also Jacox et al. (2016) for a discussion of the wind/ nitrate parameter space that maximizes chlorophyll concentrations], and (2) the idea of a high retention zone in the bay during certain conditions that can lead to a local "bloom incubator" (Ryan et al., 2008, 2014), which is discussed further below.

Fig. 7b shows monthly depth-averaged chlorophyll concentrations as a function of monthly upwelling wind stresses averaged over all years for a particular month. While there is large variability (error bars in Fig. 7b), the "Peak Upwelling" season, "Upwelling Relaxation" season, and June transition month (part of the "Upwelling Transition" period) show the largest chlorophyll concentrations and content. These results establish the link between upwelling forcing and biological productivity, but other parameters such as light levels and nutrient concentrations are needed to further describe this relation (e.g., Jacox et al., 2016). 


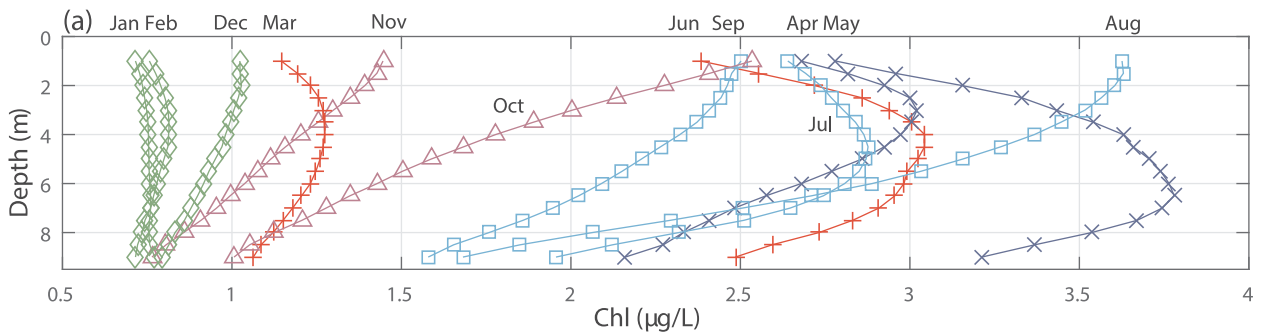

Fig. 6. Monthly vertical profiles calculated over the entire study period (2007-2013 for chlorophyll) of the (a) mean chlorophyll concentration, (b) chlorophyll variability (monthly standard deviation), and (c) vertical chlorophyll gradients. Colored symbols denote the different upwelling seasons (contiguous months) and the "Upwelling Transition" period.
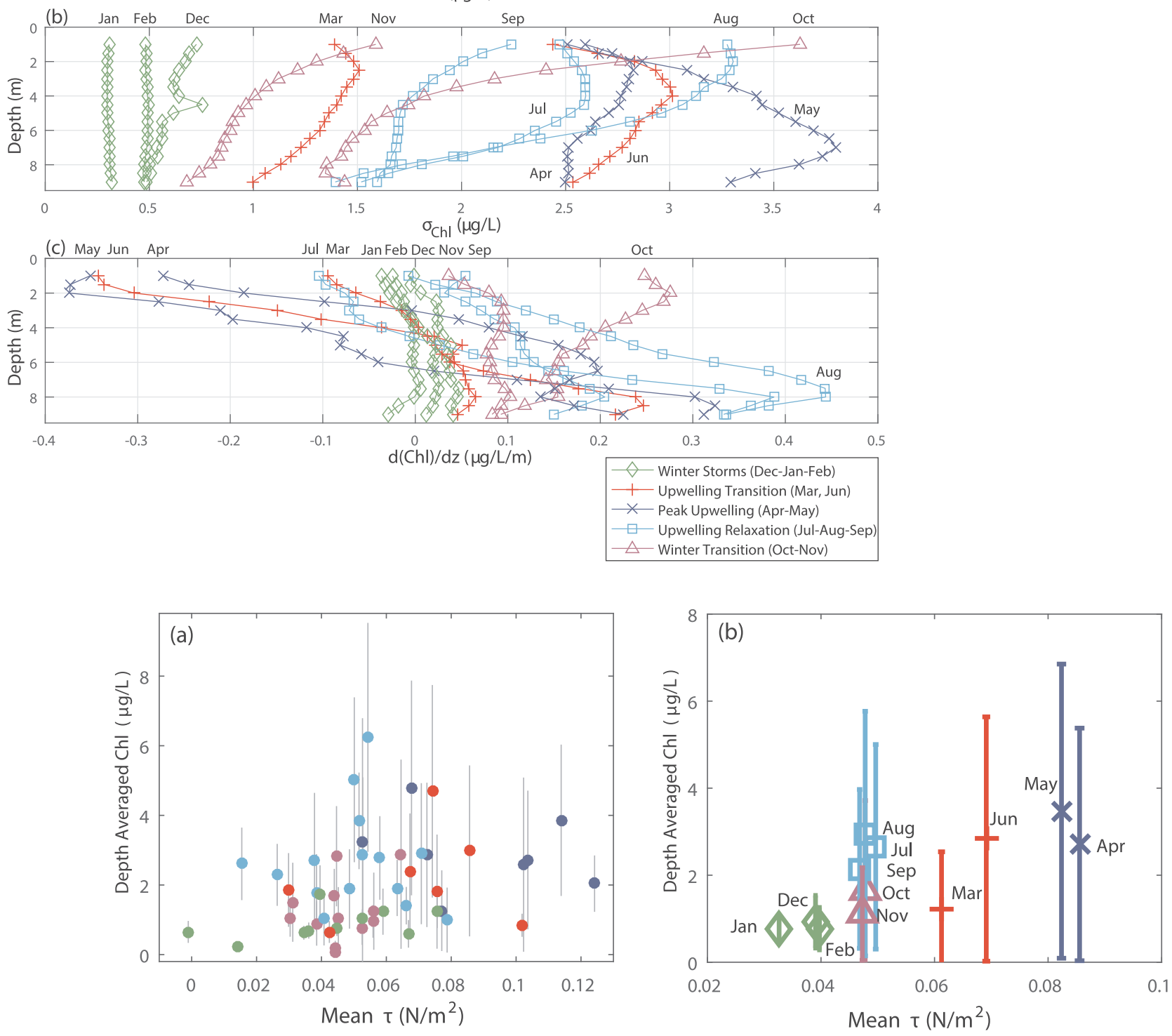

$$
\begin{array}{|l|}
\hline- \text { Winter Storms (Dec-Jan-Feb) } \\
+\quad \text { Upwelling Transition (Mar, Jun) } \\
\times \quad \text { Peak Upwelling (Apr-May) } \\
\square \quad \text { Upwelling Relaxation (Jul-Aug-Sep) } \\
\triangle \quad \text { Winter Transition (Oct-Nov) } \\
\hline
\end{array}
$$

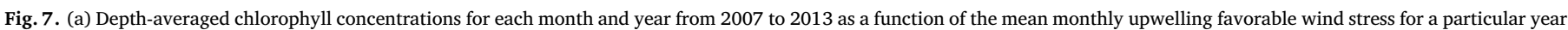

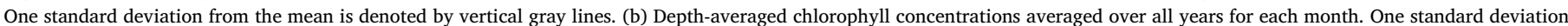
from the mean is denoted by vertical error bars. The colors denote the various upwelling seasons (contiguous months) and the "Upwelling Transition" period.

\subsection{Upwelling shadow system}

To assess the influence of the semi-enclosed embayment on temperature variability, the average seasonal cycle at the Cal Poly Pier is compared to the average temperature outside of the bay along a straight stretch of coastline (Fig. 8). Both sites show a similar annual cycle with minimum temperatures during the spring (Apr-May, "Peak Upwelling" season) followed by a rapid warming during the transition into the "Upwelling Relaxation" season. During the "Winter Storms" season (Dec-Jan-Feb), both sites display nearly identical mean temperatures. In contrast, with the start of upwelling favorable winds and the transition into the "Peak Upwelling" season (Apr-May), near-surface temperatures 


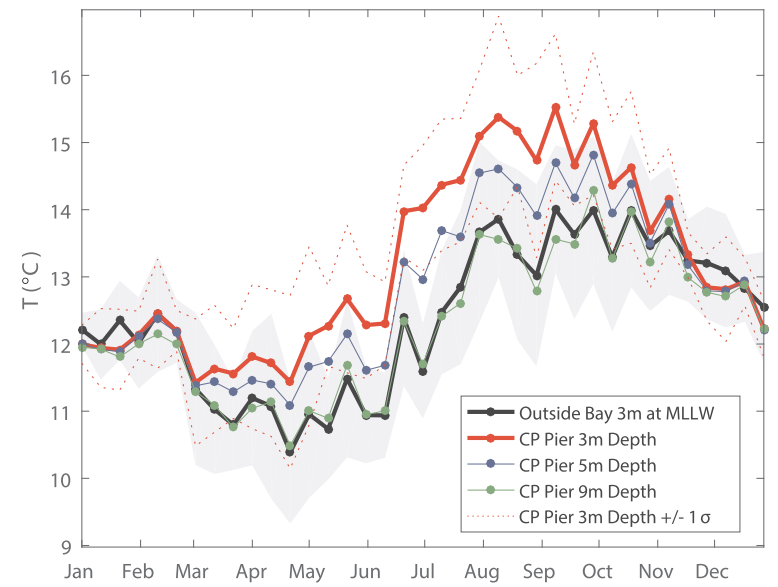

Fig. 8. Average-year temperatures comparing the Cal Poly Pier ( $3 \mathrm{~m}$ depth, red; $5 \mathrm{~m}$ depth, blue; $9 \mathrm{~m}$ depth, green) to the Outside Bay location (3 $\mathrm{m}$ depth at MLLW, black). Averages were calculated using ten-day windows and data from 2005 to 2013 . One standard deviation from the mean is shown in gray shading and dashed red lines for the Outside Bay and Cal Poly Pier (3 m depth) locations, respectively.

inside the bay at the Cal Poly Pier ( $3 \mathrm{~m}$ and $5 \mathrm{~m}$ depth) do not cool to the same extent as the Outside Bay site ( $3 \mathrm{~m}$ depth MLLW). Temperatures inside the bay near the surface remain warmer than outside of the bay throughout the spring and summer months ("Peak Upwelling" season, "Upwelling Transition" period, and "Upwelling Relaxation" season) with average temperatures inside the bay reaching almost $2{ }^{\circ} \mathrm{C}$ warmer than outside the bay at the equivalent depth. It is not until the "Winter Transition" season (Oct-Nov) that the two locations return to the same mean temperature. In contrast to the shallower measurements ( $3 \mathrm{~m}$ and $5 \mathrm{~m}$ depth) inside the bay, the near-bottom ( $9 \mathrm{~m}$ depth) temperature displays a nearly identical seasonal cycle to the shallower measurements outside the bay ( $3 \mathrm{~m}$ depth MLLW). This indicates that recently upwelled waters outside the bay likely flow through the bay at depth underneath a trapped warm surface layer, similar to other embayment systems (cf. Piñones et al., 2007; Woodson et al., 2009). This bottom flow and delivery of outside bay waters may be increased during the development of a local undercurrent observed during enhanced local diurnal wind forcing (Walter et al., 2017).

The northern portion of SLO Bay, and the location of the Cal Poly Pier profiler, is sheltered from regional northwesterly winds by local topographic features. While the temperature variability in the bay is primarily controlled by regional upwelling, the oceanic response inside the bay differs from that along the adjacent open coastline. This dynamic situation is characteristic of an "upwelling shadow" system found in bays of different sizes throughout eastern boundary current upwelling systems including Monterey Bay in central California (Graham and Largier, 1997; Ryan et al., 2008, 2014; Woodson et al., 2009; Walter et al., 2016), Antofagasta Bay in northern Chile (Piñones et al., 2007), Cartagena Bay in central Chile (Bonicelli et al., 2014), Bodega Bay in northern California (Roughan et al., 2005), and San Luis Obispo Bay in central California (this study and Walter et al., 2017), among others. In these systems, local coastline orientation and topographic features shelter the system from prevailing upwelling favorable winds, resulting in the development of a retention zone, the persistence of a warm surface layer, and inshore currents moving opposite the direction of the wind-driven surface flow. An example highlighting the upwelling shadow is seen in the NOAA Advanced Very High Resolution Radiometer (AVHRR) sea surface temperature (SST) image in Fig. 9. In this image, a strong front separates the warm water mass inside the bay (upwelling shadow) from the cold waters outside the bay (upwelling plume) that extend across the mouth of the semi-enclosed embayment. Seasonal SST composites were not calculated because of the presence of clouds during most upwelling periods that would bias calculations.

To further quantify temperature differences between the Cal Poly

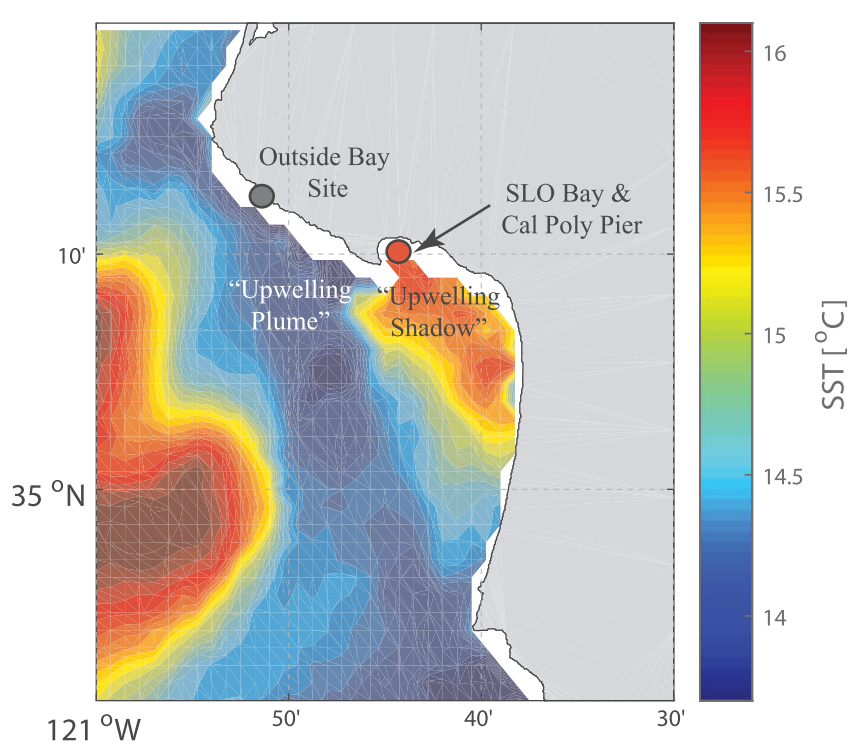

Fig. 9. AVHRR SST image from 12 October 2011 highlighting the upwelling shadow that forms inside of SLO Bay and at the Cal Poly Pier.
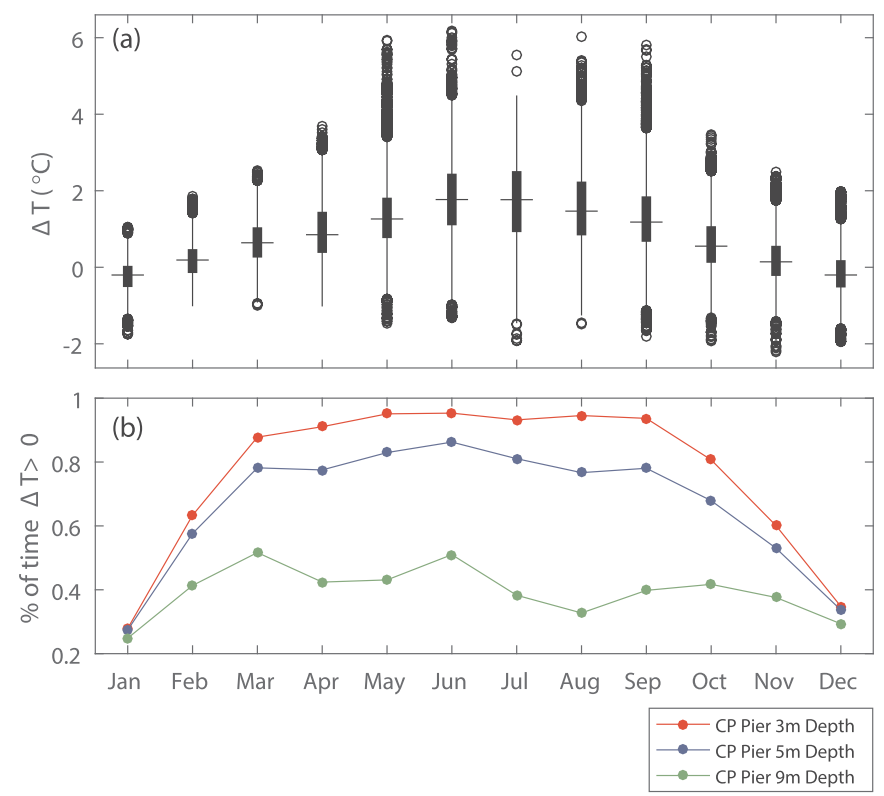

Fig. 10. (a) Median boxplots for the temperature difference $(\Delta T)$ between the Outside Bay and Cal Poly Pier ( $3 \mathrm{~m}$ depth) sites. A positive $\Delta \mathrm{T}$ indicates that the Cal Poly Pier site is warmer than the Outside Bay location. (b) Percent of the time that the Cal Poly Pier site ( $3 \mathrm{~m}$ depth, red; $5 \mathrm{~m}$ depth, blue; $9 \mathrm{~m}$ depth, green) is warmer than the Outside Bay site (i.e., $\Delta \mathrm{T}>0$ ). Both panels (a) and (b) incorporate all measurements from 2005 to 2013 and are organized by month.

Pier and Outside Bay sites, box plots organized by month are computed (Fig. 10; $\Delta \mathrm{T}$, where a positive value indicates that inside the bay was warmer than outside the bay). During the spring and summer months ("Peak Upwelling" season, "Upwelling Transition" period, and "Upwelling Relaxation" season), temperature differences are mainly positive with the upper limit of the whiskers $(\sim 2.7 \sigma$, where $\sigma$ is the standard deviation) extending well over $4{ }^{\circ} \mathrm{C}$ during June and July. During the "Winter Transition" and "Winter Storms" seasons, temperature differences are distributed about zero with a much smaller range. Fig. 10 also shows the percentage of the time where $\Delta \mathrm{T}>0$. Throughout the spring and summer months ("Peak Upwelling" season, "Upwelling Transition" period, and "Upwelling Relaxation" season), the bay is warmer than the equivalent depth outside the bay around $80-90 \%$ of the time, indicative of an upwelling shadow system. Near- 
bottom waters inside the bay ( $9 \mathrm{~m}$ depth) are warmer than outside bay waters near the surface ( $3 \mathrm{~m}$ depth MLLW) less than $50 \%$ of the time, indicative of similar temperature waters.

\section{Discussion}

\subsection{Seasonality}

Previous studies documenting seasonal changes along the California Current have focused their analysis over larger spatial scales (i.e., on the order of the California Current) and in much deeper waters, while relatively few studies have focused on smaller spatial scales (i.e., on the order of small embayments) and shallower waters. In this contribution, we consider the monthly mean and standard deviation of the upwelling favorable wind stress to define distinct upwelling seasons tuned for SLO Bay. Moreover, we build on the original analysis of García-Reyes and Largier (2012) by considering seasonal changes to the vertical distribution of temperature and chlorophyll. This is similar to the analysis of Pennington and Chavez (2000) from the well-studied, but much larger $(\sim 30 \mathrm{~km}$ wide) and deeper $(>1000 \mathrm{~m}$ in the center where the Monterey Submarine Canyon bisects the bay), Monterey Bay. Small and shallow coastal embayments, such as SLO Bay in this study, are ubiquitous in major upwelling systems around the world, but have received considerably less attention in the literature.

During the "Winter Storms" season (Dec-Jan-Feb), weak, but highly variable, winds are characteristic of episodic storm systems that tend to erode near-surface stratification and deepen the offshore thermocline through wind-driven mixing. The response in SLO Bay is a well-mixed water column with uniform temperatures and the lowest chlorophyll concentrations observed during the annual cycle, the latter of which is likely driven by a combination of reduced light availability (shorter days and higher turbidity), deep mixing of photosynthesizing phytoplankton, a depressed offshore nutricline (and thermocline), and the lack of transport of subthermocline waters rich in nutrients to the coastal region via wind-driven upwelling.

Starting in March, the upwelling intensity increases dramatically, driven by seasonal changes in the NPH (Huyer, 1983). This signals a transition (Mar of the "Upwelling Transition" period) to the classic upwelling season in California, and this time period has been termed the "spring transition" (Checkley and Barth, 2009). This is a critical time of the year as many marine organisms have life histories that are adjusted to seasonal changes in the environment (i.e., phenology; Bograd et al., 2009). This transition is typified by shoaling of the offshore thermocline and nutricline and the transport of cold, nutrient-rich waters into the nearshore (Pennington and Chavez, 2000). As the upwelling winds continue to intensify into the "Peak Upwelling" season (Apr-May), shoaling of the offshore thermocline continues due to a combination of both the positive offshore wind stress curl (i.e., Ekman pumping) that acts to lift offshore isotherms and coastal upwelling (cf., Chavez and Messié, 2009). The nearshore response is characterized by cold waters throughout the bottom portions of the water column as well as peaks in chlorophyll concentrations throughout the water column, the latter of which is presumably driven by the pumping of nutrients into the shallow photic zone. Previous research suggests that the strong upwelling during this time of the year supports fast-growing diatoms (Kudela et al., 2005). This season is also typified by the most variability in upwelling favorable winds, due to frequent wind-relaxation and reversals (Send et al., 1987). This translates into highly variable vertical temperature and chlorophyll structure in the nearshore embayment as the ocean responds to variable upwelling and cross-shelf exchange.

The second month of the "Upwelling Transition" period occurs in June, which is characterized by decreased wind stress magnitudes. This decrease in upwelling (and hence reduction in the offshore advection of warm waters in the surface Ekman layer), in addition to increased solar heat fluxes, leads to a warming of the near-surface region in SLO Bay while still maintaining high levels of biological productivity. During the
"Upwelling Relaxation" season (Jul-Aug-Sep) in the late summer, the wind stress subsides further and becomes much less variable. During this time period, strong vertical temperature and chlorophyll gradients develop with enhanced chlorophyll levels observed in the upper warm layer. This strong vertical stratification likely inhibits vertical mixing of nutrients into the warm surface layer (cf. Walter et al., 2014a). These conditions with strong thermal stratification, locally enhanced nutrient supply below the thermocline, low wind stress, and retentive properties (i.e., upwelling shadow) favor highly motile dinoflagellate blooms, which are known to migrate vertically and aggregate near the surface (Ryan et al., 2008, 2014). During the "Winter Transition" season (OctNov), vertical temperature and chlorophyll gradients start to erode as the surface layer cools until the distributions become uniform in the "Winter Storms" season (Dec-Jan-Feb).

We note that other studies, particularly in central California systems, have defined three distinct upwelling seasons: a spring and early summer upwelling season, a fall relaxation season (sometimes called the "Oceanic Season"), and a winter non-upwelling/storm season (sometimes termed the "Davidson Current Period") (Skogsberg, 1936; Largier et al., 1993; Pennington and Chavez, 2000; García-Reyes and Largier, 2012). Naturally, there are transitions between the aforementioned seasons. Here, we define contiguous months that occupy a distinct portion of the wind stress parameter space as seasons (e.g., "Peak Upwelling" in Apr-May, "Upwelling Relaxation" in Jul-Aug-Sep, "Winter Transition" in Nov-Oct, and "Winter Storms" in Dec-Jan-Feb), while the term period is used for non-contiguous months that occupy a well-defined portion of the wind stress parameter space (e.g., the "Upwelling Transition" period in Mar and Jun). As others have noted (cf. Pennington and Chavez, 2000 and the references therein; GarcíaReyes and Largier, 2012 and the references therein), interannual variability may cause differences in the timing of certain upwelling regimes (i.e., seasons and periods), particularly during the "Upwelling Transition" period and "Winter Transition" season (see further discussion of temporal variability below). It also appears that the variability in the other regimes ("Peak Upwelling", "Upwelling Relaxation", and "Winter Storms" seasons) is largely driven by synoptic variability (i.e., storm events and/or upwelling/relaxation cycles lasting days to weeks) and remains more consistent year-to-year in the Fig. 3 parameter space (not shown). Some of the major differences between this site and locations further north in central and northern California (Pennington and Chavez, 2000; García-Reyes and Largier, 2012) is that (1) peak upwelling subsides by June whereas it climaxes in June elsewhere, (2) moderate mean upwelling favorable winds persist later into the fall (i.e., "Winter Transition" season), and (3) stronger mean upwelling occurs in March.

\subsection{Scales of variability and implications}

Understanding the drivers of physical and biological variability, and the appropriate time and length scales at which these processes occur, is critical when examining the dynamics of a particular system. Temporally, this study considers an average year computed using nearly a decade of data. This averaging removes interannual variability that may be associated with a host of propagating perturbations and low-frequency basin-wide phenomena. However, it does provide a foundation on which to study interannual changes to this mean seasonal structure (e.g., North Pacific marine heatwave from 2014 to 2016, Largier et al., in prep), as well as anticipated effects of climate change on the upwelling system (cf. Bakun et al., 2015). Moreover, seasonal and monthly averages also remove higher-frequency variability associated with upwelling-relaxation cycles, offshore intrusions of eddying filaments, storm events, local diurnal wind forcing, and tidal forcing, although these features are collectively captured in the monthly standard deviation of temperature and chlorophyll distributions (Nidzieko and Largier, 2013; Walter et al., 2017). The observations presented here are meant to provide a framework on which to study changes to this 
seasonal structure and assess the relative contribution of these higherfrequency features to nearshore variability (e.g., local diurnal wind forcing in SLO Bay in Walter et al., 2017), as well as future climatic changes. Understanding the dominant seasonal signal allows for better predictions of dynamically and ecologically important events. This may include, for example, periods where there is a greater likelihood of seeing environmental conditions favorable for HABs (Kudela et al., 2005), extended pooling of subthermocline waters low in $\mathrm{DO}$ and $\mathrm{pH}$ (Booth et al., 2012; Walter et al., 2014b; Boehm et al., 2015), or stratified conditions that are favorable for increased frontal activity and high-frequency internal waves that promote active mixing in the water column (Walter et al., 2016, 2017).

Spatially, the dynamics of upwelling systems are modulated due to the effects of varying coastline orientation and topographic features. Small-scale coastal embayments exist throughout boundary current upwelling systems and many have been shown to play substantial roles in shaping the physical and biological environment by amplifying and/ or reducing the influence of upwelling and downwelling processes and local circulation patterns (see Section 3.3). Here, we document an upwelling shadow system that may promote enhanced residence times in SLO Bay and a nearshore retention zone. These upwelling shadow systems, which have been termed local bloom incubators, promote enhanced stratification and reduced wind-driven mixing, conditions that are favorable for elevated chlorophyll levels, surface aggregations of dinoflagellates, and HABs (Ryan et al., 1998, 2014; Kudela et al., 2005). Understanding the role of these warmer nearshore retention zones in the broader ecology of the region may be particularly important for the transport and recruitment of larvae (Roughan et al., 2005), as well as the poleward expansion of species. For example, this region regularly receives intrusions of warm surface water that originate from offshore eddies generated along the upwelling front near Point Conception (Nidzieko and Largier, 2013), or from poleward propagating buoyant plumes generated during regional wind relaxations around Point Conception (Washburn et al., 2011; Suanda et al., 2016), a major marine biogeographic boundary (Blanchette et al., 2007; Checkley and Barth, 2009). It is possible that this warm upwelling shadow region could serve as a "stepping-stone refuge" for larvae of poleward expanding species, although further field data would be required to verify this hypothesis.

Due to a lack of long-term platforms and sensors with sufficient vertical resolution to resolve vertical variability in shallow waters, vertical variability is often overlooked. This is despite the fact that finescale vertical processes, in comparison to large-scale horizontal processes, may have an equal, if not more important, influence on physical processes, marine ecosystem dynamics and functioning, and the distribution and abundance of marine organisms (Sullivan et al., 2010; Durham and Stocker, 2012). Here, highly resolved vertical profiles highlight the presence of strong vertical gradients in both temperature and chlorophyll. The strong stratification that develops seasonally has the ability to control physical (and biological) processes in the bay. In particular, Walter et al. (2017) documented the interaction of strong local diurnal wind forcing in SLO bay with existing stratification, leading to frontogenesis, the propagation of highly nonlinear internal waves and solitons, and a local undercurrent. Moreover, the vertical distribution of chlorophyll and fine scale patchiness is increasingly recognized as an important biological signature in the coastal ocean (Sullivan et al., 2010; Durham and Stocker, 2012). In addition to vertical variations, lateral gradients in stratification and water properties across the upwelling shadow front likely produce sharp changes in plankton communities (Ryan et al., 2014). Future studies should focus on further resolving spatial changes in stratification and water properties (e.g., chlorophyll, dissolved oxygen, plankton communities, etc.) inside and outside of the upwelling shadow system.

\section{Conclusions}

Given the ubiquity of small-scale coastal embayments in upwelling systems worldwide, a better understanding of their role in both regional and local oceanography and marine ecosystems is warranted. This contribution describes, for the first time in detail, nearly a decade of oceanographic data collected using an automated water-column profiling system at the end of the Cal Poly Pier, located in a shallow coastal embayment in a poorly sampled region along the California coastline and near a major marine biogeographic boundary. Using full watercolumn measurements of temperature and chlorophyll, we consider the oceanic response to seasonally-variable coastal upwelling. Rather than using a bimodal description of upwelling seasonality (i.e., upwelling and non-upwelling seasons), distinct upwelling seasons (contiguous months) and a transition period (non-contiguous months) are defined by considering both the mean and standard deviation of the monthly upwelling favorable wind stress: "Winter Storms" season (Dec-Jan-Feb), "Upwelling Transition" period (Mar and Jun), "Peak Upwelling" season (Apr-May), "Upwelling Relaxation" season (Jul-Aug-Sep), and "Winter Transition" season (Oct-Nov). The seasonal structure of temperature and chlorophyll variability in response to these upwelling regimes provides a strong foundation for an improved understanding of the interplay between regional (large-scale) and local (small-scale) processes. Future studies should further assess small-scale spatial structure and variability throughout the upwelling shadow system to better understand the role of differential exposure to regional upwelling on local processes (both physical and biological).

\section{Acknowledgements}

We acknowledge support from the NOAA IOOS program through CeNCOOS (Shore Stations) and SCCOOS (HABs) for data collected at the Cal Poly Pier. R. Walter was supported by California Sea Grant (Award NA14OAR4170075). K. Armenta and B. Shearer were supported by the Frost Summer Scholarship Program at Cal Poly. We thank a countless number of students, technicians, staff, and former PIs on the IOOS grants (Dean Wendt and Mark Moline) for their help with the operation and maintenance of the pier profiler over the years. We acknowledge the NOAA Coast Watch Program and the NOAA NWS Monterey Regional Forecast Office for SST data. Digital elevation model data for the region were obtained from NOAA's National Geophysical Data Center. Comments and suggestions from three anonymous reviewers greatly improved the quality of the manuscript.

\section{References}

Bakun, A., Black, B.A., Bograd, S.J., García-Reyes, M., Miller, a.J., Rykaczewski, R.R., Sydeman, W.J., 2015. Anticipated effects of climate change on coastal upwelling ecosystems. Curr. Clim. Change Rep. 85-93. http://dx.doi.org/10.1007/s40641-0150008-4.

Blanchette, C.A., Helmuth, B., Gaines, S.D., 2007. Spatial patterns of growth in the mussel, Mytilus californianus, across a major oceanographic and biogeographic boundary at Point Conception, California, USA. J. Exp. Mar. Biol. Ecol. 340, 126-148. http://dx.doi.org/10.1016/j.jembe.2006.09.022.

Boehm, A.B., Jacobson, M.Z., O’Donnell, M.J., Sutula, M., Wakefield, W.W., Weisberg, S.B., Whiteman, E., 2015. Ocean acidification science needs for natural resource managers of the North American west coast. Oceanography 28 (2), 170-181. http:// dx.doi.org/10.5670/oceanog.2015.40.

Bograd, S.J., Schroeder, I., Sarkar, N., Qiu, X., Sydeman, W.J., Schwing, F.B., 2009. Phenology of coastal upwelling in the California Current. Geophys. Res. Lett. 36, 1-5. http://dx.doi.org/10.1029/2008GL035933.

Bond, N.A., Cronin, M.F., Freeland, H., Mantua, N., 2015. Causes and impacts of the 2014 warm anomaly in the NE Pacific. Geophys. Res. Lett. 42, 3414-3420. http://dx.doi. org /10.1002/2015GL063306.

Bonicelli, J., Moffat, C., Navarrete, S.A., Largier, J.L., Tapia, F.J., 2014. Spatial differences in thermal structure and variability within a small bay: interplay of diurnal winds and tides. Cont. Shelf Res. 88, 72-80. http://dx.doi.org/10.1016/j.csr.2014.07.009.

Booth, J.A.T., McPhee-Shaw, E.E., Chua, P., Kingsley, E., Denny, M., Phillips, R., Bograd, S.J., Zeidberg, L.D., Gilly, W.F., 2012. Natural intrusions of hypoxic, low pH water into nearshore marine environments on the California coast. Cont. Shelf Res. 45, 108-115. http://dx.doi.org/10.1016/j.csr.2012.06.009. 
Botsford, L.W., Lawrence, C.A., Dever, E.P., Hastings, A., Largier, J., 2006. Effects of variable winds on biological productivity on continental shelves in coastal upwelling systems. Deep. Res. Part II Top. Stud. Oceanogr. 53, 3116-3140. http://dx.doi.org/ 10.1016/j.dsr2.2006.07.011.

Chao, Y., Farrara, J.D., Zhang, H., Armenta, K.J., Centurioni, L., Chavez, F., Girton, J.B., Rudnick, D., Walter, R.K., 2017. Development, implementation, and validation of a California coastal ocean modeling, data assimilation, and forecasting system. Deep Sea Res. Part II Top. Stud. Oceanogr. http://dx.doi.org/10.1016/j.dsr2.2017.04.013.

Chavez, F.P., Messié, M., 2009. A comparison of eastern boundary upwelling ecosystems. Prog. Oceanogr. 83, 80-96. http://dx.doi.org/10.1016/j.pocean.2009.07.032.

Chavez, F.P., Messié, M., Pennington, J.T., 2011. Marine primary production in relation to climate variability and change. Ann. Rev. Mar. Sci. 3, 227-260. http://dx.doi.org/ 10.1146/annurev.marine.010908.163917.

Checkley, D.M., Barth, J.A., 2009. Patterns and processes in the California Current system. Prog. Oceanogr. 83, 49-64. http://dx.doi.org/10.1016/j.pocean.2009.07. 028.

Dorman, C.E., Winant, C.D., 1995. Buoy observations of the atmosphere along the west coast of the United States, 1981-1990. J. Geophys. Res. Ocean. 100, 16029-16044. http://dx.doi.org/10.1029/95JC00964.

Durham, W.M., Stocker, R., 2012. Thin phytoplankton layers: characteristics, mechanisms, and consequences. Ann. Rev. Mar. Sci. 4, 177-207. http://dx.doi.org/10.1146/ annurev-marine-120710-100957.

Fewings, M.R., Washburn, L., Dorman, C.E., Gotschalk, C., Lombardo, K., 2016. Synoptic forcing of wind relaxations at Pt. Conception, California. J. Geophys. Res. Ocean. 121, 5711-5730. http://dx.doi.org/10.1002/2016JC011699.

Flynn, K.R., Fewings, M.R., Gotschalk, C., Lombardo, K., 2017. Large-scale anomalies in sea-surface temperature and air-sea fluxes during wind relaxation events off the United States West Coast in summer. J. Geophys. Res. Ocean. 122, 2574-2594. http://dx.doi.org/10.1002/2016JC012613.

García-Reyes, M., Largier, J.L., 2012. Seasonality of coastal upwelling off central and northern California: new insights, including temporal and spatial variability. J. Geophys. Res. http://dx.doi.org/10.1029/2011JC007629.

García-Reyes, M., Largier, J.L., Sydeman, W.J., 2014. Synoptic-scale upwelling indices and predictions of phyto- and zooplankton populations. Prog. Oceanogr. 120, 177-188. http://dx.doi.org/10.1016/j.pocean.2013.08.004.

Gentemann, C.L., Fewings, M.R., García-Reyes, M., 2016. Satellite sea-surface temperatures along the west coast of the United States during the 2014-2016 northeast Pacific marine heat wave. Geophys. Res. Lett. 312-319. http://dx.doi.org/10.1002/ 2016GL071039.

Gentien, P., Donaghay, P., Yamazaki, H., Raine, R., Reguera, B., Osborn, T., 2005. Harmful algal blooms harmful in stratified environments. Oceanography 18 , 172-183. http://dx.doi.org/10.1016/0140-6736(93)92085-8.

Graham, W.M., Largier, J.L., 1997. Upwelling shadows as nearshore retention sites: the example of northern Monterey Bay. Cont. Shelf Res. 17, 509-532. http://dx.doi.org/ 10.1016/S0278-4343(96)00045-3.

Huyer, A., 1983. Coastal upwelling in the California current system. Prog. Oceanogr. 12, 259-284. http://dx.doi.org/10.1016/0079-6611(83)90010-1.

Jacox, M.G., Hazen, E.L., Bograd, S.J., 2016. Optimal environmental conditions and anomalous ecosystem responses: constraining bottom-up controls of phytoplankton biomass in the California Current system. Sci. Rep. 6, 27612. http://dx.doi.org/10. 1038/srep27612.

Kudela, R., Pitcher, G., Probyn, T., Figueiras, F., Moita, T., Trainer, V., 2005. Harmful algal blooms in coastal upwelling systems. Oceanography 18, 184-197.

Large, W.G., Pond, S., 1981. Open ocean momentum flux measurements in moderate to strong winds. J. Phys. Oceanogr. http://dx.doi.org/10.1175/1520-0485(1981) $011<0324$ :OOMFMI > 2.0.CO;2.

Largier, J.L., Magnell, B.A., Winant, C.D., 1993. Subtidal circulation over the northern California shelf. J. Geophys. Res. 98, 18147. http://dx.doi.org/10.1029/93JC01074.

Nidzieko, N.J., Largier, J.L., 2013. Inner shelf intrusions of offshore water in an upwelling system affect coastal connectivity. Geophys. Res. Lett. 40, 5423-5428. http://dx.doi. org/10.1002/2013GL056756.

Pennington, T.J., Chavez, F.P., 2000. Seasonal fluctuations of temperature, salinity, nitrate, chlorophyll and primary production at station H3/M1 over 1989-1996 in
Monterey Bay, California. Deep. Res. Part II Top. Stud. Oceanogr. 47, 947-973. http://dx.doi.org/10.1016/S0967-0645(99)00132-0.

Piñones, A., Castilla, J.C., Guiñez, R., Largier, J.L., 2007. Nearshore surface temperatures in Antofagasta Bay (Chile) and adjacent upwelling centers. Cienc. Mar. 33, 37-48.

Roughan, M., Mace, A.J., Largier, J.L., Morgan, S.G., Fisher, J.L., Carter, M.L., 2005. Subsurface recirculation and larval retention in the lee of a small headland: a variation on the upwelling shadow theme. J. Geophys. Res. C Ocean. 110, 1-18. http:// dx.doi.org/10.1029/2005JC002898.

Ryan, J.P., Gower, J.F.R., King, S.A., Bissett, W.P., Fischer, A.M., Kudela, R.M., Kolber, Z., Mazzillo, F., Rienecker, E.V., Chavez, F.P., 2008. A coastal ocean extreme bloom incubator. Geophys. Res. Lett 35. pp. 4-8. http://dx.doi.org/10.1029/ 2008GL034081.

Ryan, J.P., McManus, M.A., Kudela, R.M., Lara Artigas, M., Bellingham, J.G., Chavez, F.P., Doucette, G., Foley, D., Godin, M., Harvey, J.B.J., Marin, R., Messié, M., Mikulski, C., Pennington, T., Py, F., Rajan, K., Shulman, I., Wang, Z., Zhang, Y., 2014 Boundary influences on HAB phytoplankton ecology in a stratification-enhanced upwelling shadow. Deep. Res. Part II Top. Stud. Oceanogr. 101, 63-79. http://dx.doi. org/10.1016/j.dsr2.2013.01.017.

Send, U., Beardsley, R.C., Winant, C.D., 1987. Relaxation from upwelling in the coastal ocean dynamics experiment. J. Geophys. Res. 92, 1683-1698.

Skogsberg, T., 1936. Hydography of Monterey Bay, California. Thermal conditions, 19291933. Trans. Am. Philos. Soc. 29, 1-152. http://dx.doi.org/10.1080/ 14786443908649806.

Steinbeck, J.R., Schiel, D.R., Foster, M.S., 2005. Detecting long-term change in complex communities: a case study from the rocky intertidal zone. Ecol. Appl. 15, 1813-1832. http://dx.doi.org/10.1890/04-1046.

Suanda, S.H., Kumar, N., Miller, A.J., Di Lorenzo, E., Haas, K., Cai, D.H., Edwards, C.A., Washburn, L., Fewings, M.R., Torres, R., Feddersen, F., 2016. Wind relaxation and a coastal buoyant plume north of Pt. conception, CA: observations, simulations, and scalings. J. Geophys. Res. 121, 7455-7475. http://dx.doi.org/10.1002/ 2016 jc011919.

Sullivan, J.M., McManus, M.A., Cheriton, O.M., Benoit-Bird, K.J., Goodman, L., Wang, Z., Ryan, J.P., Stacey, M., Van Holliday, D., Greenlaw, C., Moline, M.A., McFarland, M., 2010. Layered organization in the coastal ocean: an introduction to planktonic thin layers and the LOCO project. Cont. Shelf Res. 30, 1-6. http://dx.doi.org/10.1016/j. csr.2009.09.001.

Walter, R.K., Brock Woodson, C., Arthur, R.S., Fringer, O.B., Monismith, S.G., 2012 Nearshore internal bores and turbulent mixing in southern Monterey Bay. J. Geophys. Res. Ocean. 117. http://dx.doi.org/10.1029/2012JC008115.

Walter, R.K., Phelan, P.J., 2016. Internal bore seasonality and tidal pumping of subthermocline waters at the head of the Monterey submarine canyon. Cont. Shelf Res. 116, 42-53. http://dx.doi.org/10.1016/j.csr.2016.01.015.

Walter, R.K., Reid, E.C., Davis, K.A., Armenta, K.J., Merhoff, K., Nidzieko, N.J., 2017. Local diurnal wind-driven variability and upwelling in a small coastal embayment. J. Geophys. Res. Ocean. 122, 955-972. http://dx.doi.org/10.1002/2016JC012466.

Walter, R.K., Squibb, M.E., Woodson, C.B., Koseff, J.R., Monismith, S.G., 2014a. Stratified turbulence in the nearshore coastal ocean: dynamics and evolution in the presence of internal bores. J. Geophys. Res. C Ocean. 119, 8709-8730. http://dx.doi.org/10. 1002/2014JC010396.

Walter, R.K., Stastna, M., Woodson, C.B., Monismith, S.G., 2016. Observations of non linear internal waves at a persistent coastal upwelling front. Cont. Shelf Res. 117, 100-117. http://dx.doi.org/10.1016/j.csr.2016.02.007.

Walter, R.K., Woodson, C.B., Leary, P.R., Monismith, S.G., 2014b. Connecting winddriven upwelling and offshore stratification to nearshore internal bores and oxygen variability. J. Geophys. Res. Ocean. 119, 3517-3534. http://dx.doi.org/10.1002/ 2014JC009998.

Washburn, L., Fewings, M.R., Melton, C., Gotschalk, C., 2011. The propagating response of coastal circulation due to wind relaxations along the central California coast. J. Geophys. Res. Ocean. 116. http://dx.doi.org/10.1029/2011JC007502.

Woodson, C.B., Washburn, L., Barth, J.A., Hoover, D.J., Kirincich, A.R., McManus, M.A., Ryan, J.P., Tyburczy, J., 2009. Northern Monterey Bay upwelling shadow front observations of a coastally and surface-trapped buoyant plume. J. Geophys. Res. Ocean. 114. http://dx.doi.org/10.1029/2009JC00562. 